\title{
Third Order Nonlinear Properties of Pure and Na Doped L-Arginine Acetate Single Crystal by Z-scan Technique
}

\author{
P. UMARANI ${ }^{1}$, S. KALAINATHAN ${ }^{2}$ and K. JAGANNATHAN ${ }^{1}$ \\ 'Department of Physics, SRM University, Vadapalani, Chennai-620026, India. \\ ${ }^{2}$ Centre for Crystal Growth, VIT University, Vellore - 632 014, India. \\ ${ }^{*}$ Corresponding author E-mail Address: kjagan81@gmail.com
}

http://dx.doi.org/10.13005/ojc/320122

(Received: October 05, 2015; Accepted: March 14, 2016)

\begin{abstract}
Single crystals of pure and Na doped L-arginine acetate (LAA) has been successfully grown from aqueous solution by slow evaporation technique. The crystalline qualities of the grown crystals were confirmed by powder X-ray diffraction studies. The nonlinear refractive index $\mathrm{n}_{2}$ and nonlinear susceptibility $\chi^{(3)}$ have been measured through the Z-scan technique. The results indicate that the compound exhibits reverse saturation absorption and self defocusing performance. Non-linear absorption co-efficient $(\beta)$, the non-linear refractive index $\left(n_{2}\right)$, the real and imaginary parts of nonlinear susceptibility $\chi^{(3)}$ have been measured at $632.8 \mathrm{~nm}$.
\end{abstract}

Key words: Crystal, Z-scan Technique, Na doped L-arginine acetate (LAA).

\section{INTRODUCTION}

L-arginine acetate (LAA) is one of the prominent members of the amino acid family ${ }^{1}$ are identified as the most promising organic nonlinear material. Recent studies reveals that LAA possess excellent optical, thermal, mechanical properties, these makes LAA is potential material for photonic devices $^{2}$. This paper deals with the third order non-linear optical properties of L-arginine acetate pure and doped crystal by Z-scan technique. The Z-scan technique ${ }^{3,4,5,6}$ is a popular method for the measurement of optical nonlinearities of materials, because of its high sensitivity and simplicity. One can simultaneously measure the magnitude and sign of the non-linear refraction and non-linear absorption, which are associated with the real part $\chi_{B}^{\left({ }^{3)}\right.}$ and imaginary part $\chi^{(3)}$ of the third order non-linear susceptibilities. The Z-scan technique has been used to measure the non-linear optical properties of semiconductors ${ }^{7}$ dielectrics ${ }^{8,9}$ organic or carbonbased molecules ${ }^{10,11}$ and liquid crystals ${ }^{12,13}$. In this work we report the growth of $\mathrm{L}$-arginine acetate pure and doped single crystals from aqueous solution. Single X-ray diffraction, Power X-ray diffraction and $Z$-scan measurements were carried out. Z-scan results reveals that $L$-arginine single crystal is a potential candidate for the optical switching ${ }^{14}$ and optical limiting ${ }^{15}$ applications. 


\section{Material Synthesis and Crystal growth}

Commercially available L-arginine (MERKIndiaLtd.), and acetic acid were mixed in stoichiometric ratio with excess of double distilled water to synthesize LAA source material. Sodium hydroxide $0.1,0.20 .3$ and $0.4 \%$ weight percentage powder form was added to the pure source material. The synthesized salts were purified by repeated recrystallization process in double distilled water. The good qualities of crystal were formed only 0.3 and $0.4 \%$ of sodium hydroxide. The harvested crystals of pure and doped crystal as shown in fig 1. The crystals were grown by slow evaporation method.

$\left(\mathrm{NH}_{2}\right) \mathrm{NHCNH}\left(\mathrm{CH}_{2}\right)_{3} \mathrm{CH}\left(\mathrm{NH}_{2}\right) \mathrm{COOH}+\mathrm{CH}_{3} \mathrm{CH}_{3} \mathrm{COOH}$ $+\mathrm{NaOH} \rightarrow\left(\mathrm{NH}_{2}\right)_{2}{ }^{+} \mathrm{CNH}\left(\mathrm{CH}_{2}\right)_{3} \mathrm{CH}\left(\mathrm{NH}_{3}\right)^{+} \mathrm{Na}^{+} . \mathrm{COO}-\mathrm{CH}_{3}$ $\mathrm{COO} \cdot \mathrm{OH}$

\section{RESULT AND DISCUSSION}

\section{Power XRD}

The Fig. 2 shows the powder X-ray diffraction pattern of pure and doped crystals respectively. The powder sample was scanned in steps of $0.02 \%$ for a time interval of $10 \mathrm{~s}$ over a $2 \theta$ range of $10-80$ in Xport high score. All the observed reflection lines in XRD pattern were indexed using the computer program PROZKI. The observed lattice dimensions are good in agreement with the reported literature values of LAA. The powder XRD also mostly same for pure and doped LAA. The first peak is missing in $\mathrm{Na}$ doped LAA.

\section{Z-scan Measurement}

The Z-scan technique is a highly sensitive and a useful tool for determining the magnitude and sign of nonlinear index of refraction $\left(n_{2}\right)$ of solids, liquid solutions and thin films. In this experiment, the third-order NLO properties of the title crystal were investigated by using $\mathrm{He}-\mathrm{Ne}$ laser $(5 \mathrm{~mW})$ of wavelength at $632.8 \mathrm{~nm}$ was used as a source and the beam diameter is $0.5 \mathrm{~mm}$. It was focused with Gaussian filter to convert input laser beam into Gaussian form. The Gaussian beam TEM mode is passed through a convex lens with a focal length $30 \mathrm{~mm}$. The diameter of the Gaussian beam waist $\omega_{0}$ at the focal length is 12.05im. The sample is translated across in the $+Z$ to $-Z$ axial direction by the control of the stepper motor in order to vary the incident intensity falling on the crystal surface. The far filed transmittance intensity variations are measured through the closed aperture by using digital power meter (Field master GS-coherent). From the closed aperture Z-scan curve, the pre-focal valley to postfocal peak configuration of the aperture curve suggests that the third order nonlinear refractive index change is positive. It is indicating a self-focusing effect which is due to the reduced transmittance and large beam divergence through the far field aperture. An open aperture Z Scan data, the measurements were repeated the sample was moved along the focal point and without placing aperture in order to capture the entire transmitted beam by the detector. The essential criteria of sample thickness condition was satisfied for this measurement with the Rayleigh length $(\mathrm{ZR}=\mathrm{K}>\mathrm{L}$, where $\mathrm{L}$ denotes its thickness, and $\mathrm{ZR}$ is the diffraction length of the Gaussian beam) [16] The value of Rayleigh length of a Gaussian laser beam can be calculated using the relation

$$
\mathrm{Z}_{\mathrm{R}}=\mathrm{K} \omega_{0}^{2} / 2
$$

where $\mathrm{K}$ is the wave vector $(\mathrm{K}=2 \pi / \lambda$ $\left(9.924 \times 10^{6} \mathrm{~m}^{-1}\right)$ and $\omega_{0}$ is the beam waist radius at the focal point given by

$$
\omega_{0}=f \lambda / D
$$

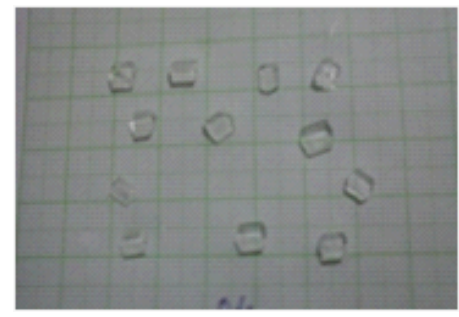

C

Fig. 1: Grown crystal of (a) Pure, (b) 0.3 and (c) $0.4 \%$ Na doped 
where $f$ is the focal length of the lens used, $\lambda$ is the wavelength of the source and $D$ is the beam radius at the lens. The difference between the transmittance change of peak and valley $(\Delta T p$ $\Delta$ "p $1 / 2$ " $\Delta$ ) is evaluated by

$$
\Delta \mathrm{T}_{p-v}=0.406(1-\mathrm{S})^{0.25} \mathrm{I} \Delta \phi_{0} \mathrm{I}
$$

where $S$ is the aperture linear transmittance and $r_{a}$ is the radius of the aperture and $\omega_{a}$ is the beam radius at the aperture. The linear transmittance and nonlinear refractive index $\left(\mathrm{n}_{2}\right)$ of the crystal was calculated by the using the relations[18]

$$
\begin{gathered}
\mathrm{S}=1-\exp \left(-2 r_{a}^{2} / \varepsilon_{\mathrm{a}}{ }^{2}\right) \\
\mathrm{n}_{2}=\Delta \Phi_{0} / \mathrm{kl}_{0} \mathrm{~L}_{\text {eff }}
\end{gathered}
$$

where $I_{0}$ is the intensity of the laser beam at the focal point and $L_{\text {eff }}$ is an effective thickness of the crystal which can be calculated by using the relation $L_{\text {eff }}=[1--\exp (-\alpha L)] / \alpha$. Here, $\alpha$ is the linear absorption, and $\mathrm{L}$ is the thickness of the crystal. From the open aperture curve, the nonlinear absorption coefficient $(\beta)$ can be determined using the following relation ${ }^{17}$

$$
\beta=2 \sqrt{ } 2 \Delta T / I_{0} L_{\text {eff }}
$$

where $\Delta T$ is the one valley value at the open aperture Z-scan curve. The value of â will be negative for saturated absorption and positive for two photon absorption processes. ${ }^{16}$ The calculated values of $n 2$ and $\beta$ was be used to determine the real and imaginary parts of the third-order nonlinear optical susceptibility can be obtained as

$$
\begin{aligned}
& \operatorname{Re} \chi^{3)}(\mathrm{esu})=10^{-4}\left(\varepsilon_{0} \mathrm{C}^{2} \mathrm{n}_{0}{ }^{2} \mathrm{n}_{2}\right) / \pi \\
& \operatorname{Im} \chi^{(3)}(\mathrm{esu})=10^{-2}\left(\varepsilon_{0} \mathrm{C}^{2} \mathrm{n}_{0} \lambda \beta\right) / 4 \pi^{2}
\end{aligned}
$$

where and $\varepsilon_{0}$ is the permittivity of free space $\left(8.8518 \times 10^{-12} \mathrm{~F} / \mathrm{m}\right), \mathrm{n}_{0}$ is the linear refractive index of the crystal and $C$ is the velocity of light in vacuum. The absolute value of the third order nonlinear optical susceptibility $\div^{(3)}$ is thus

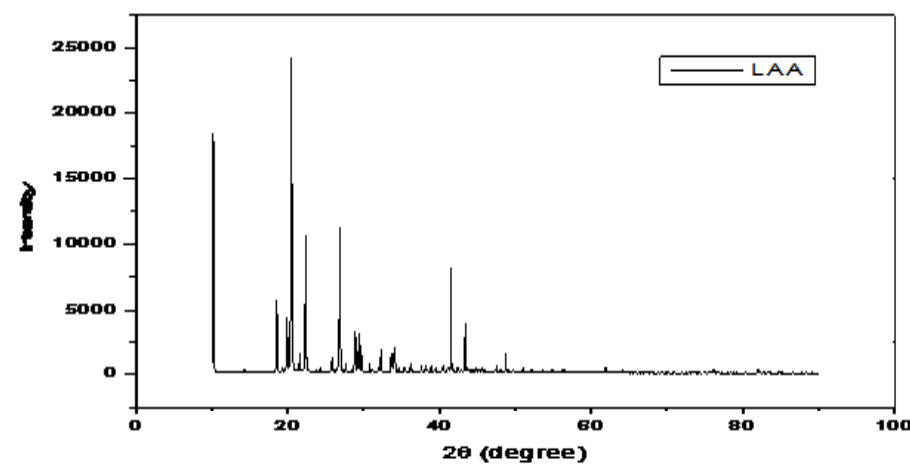

a

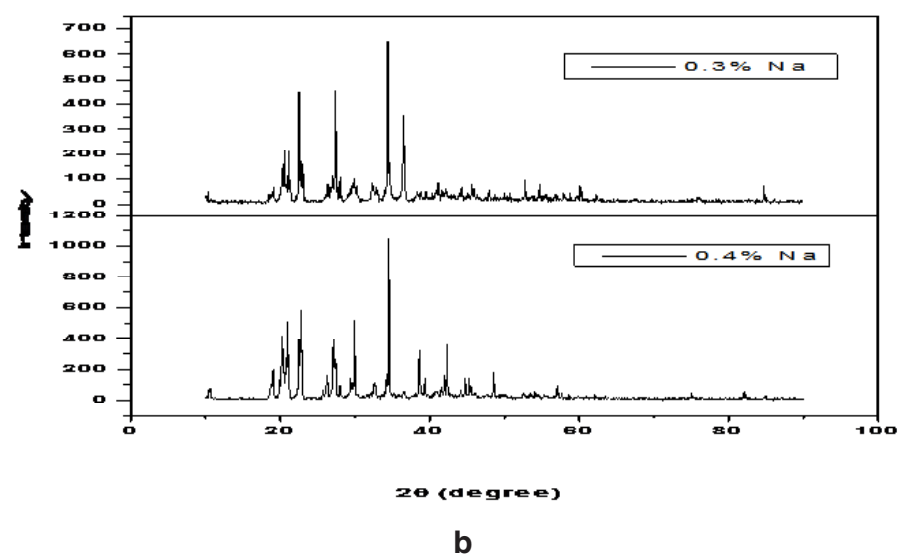

Fig. 2: X-Ray diffraction pattern of (a) pure, (b) doped crystal 


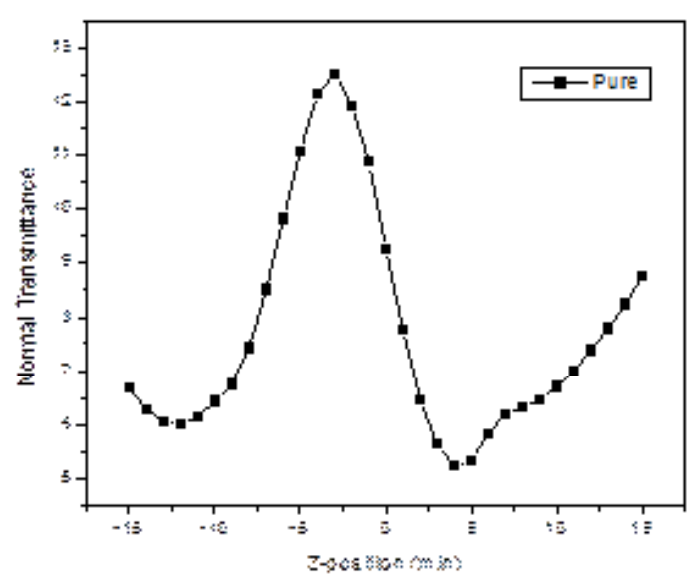

a

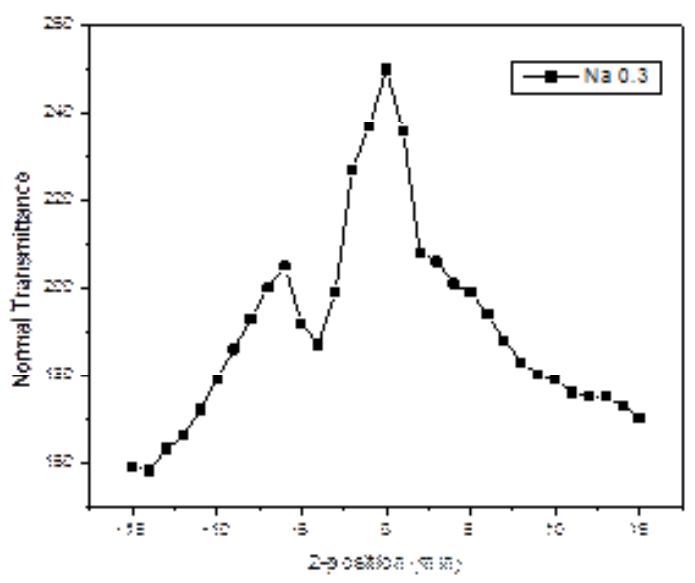

b

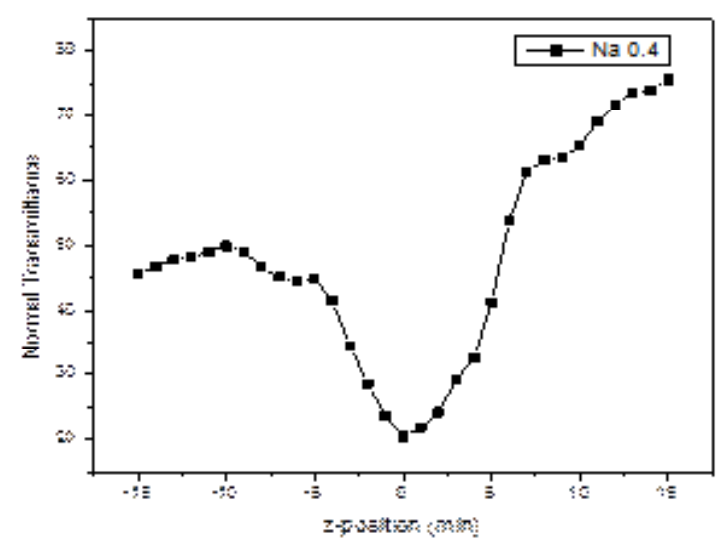

C

Fig. 3: Open aperture curve of Pure and doped crystal

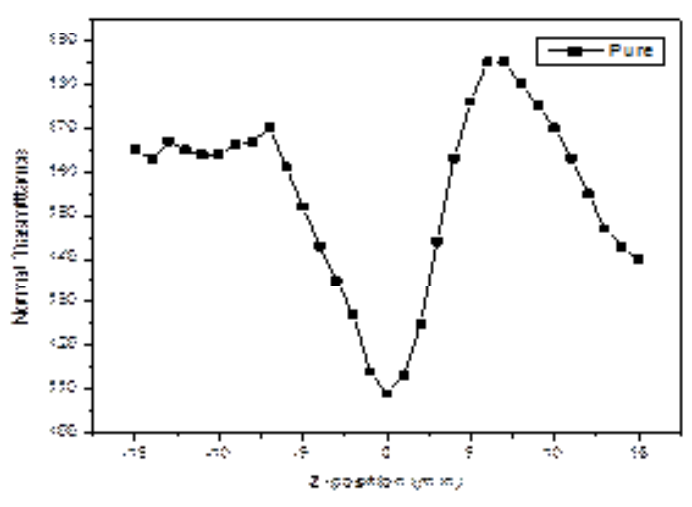

a

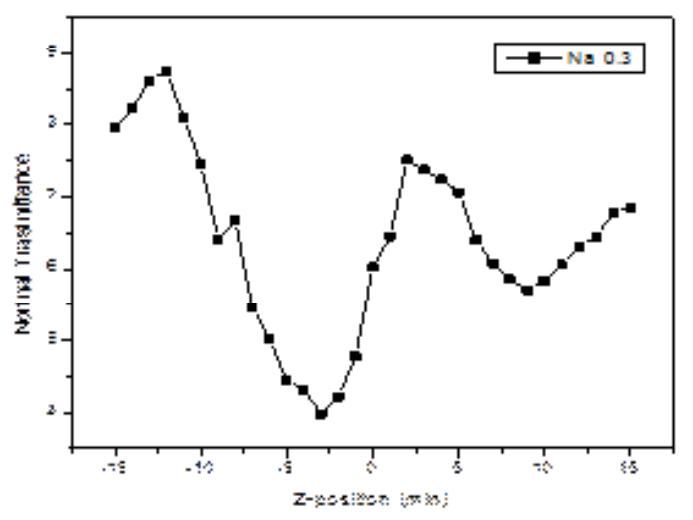

b

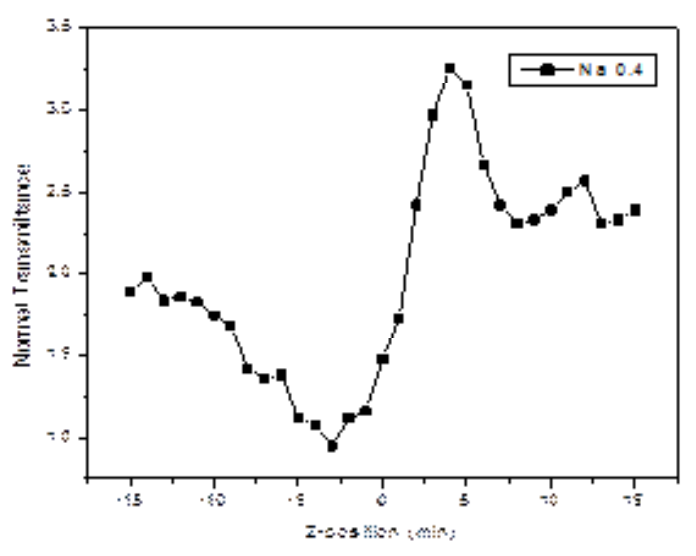

C

Fig. 4: Closed aperture curve of Pure and doped crystal 
Table 3: Z-scan measurement calculated values

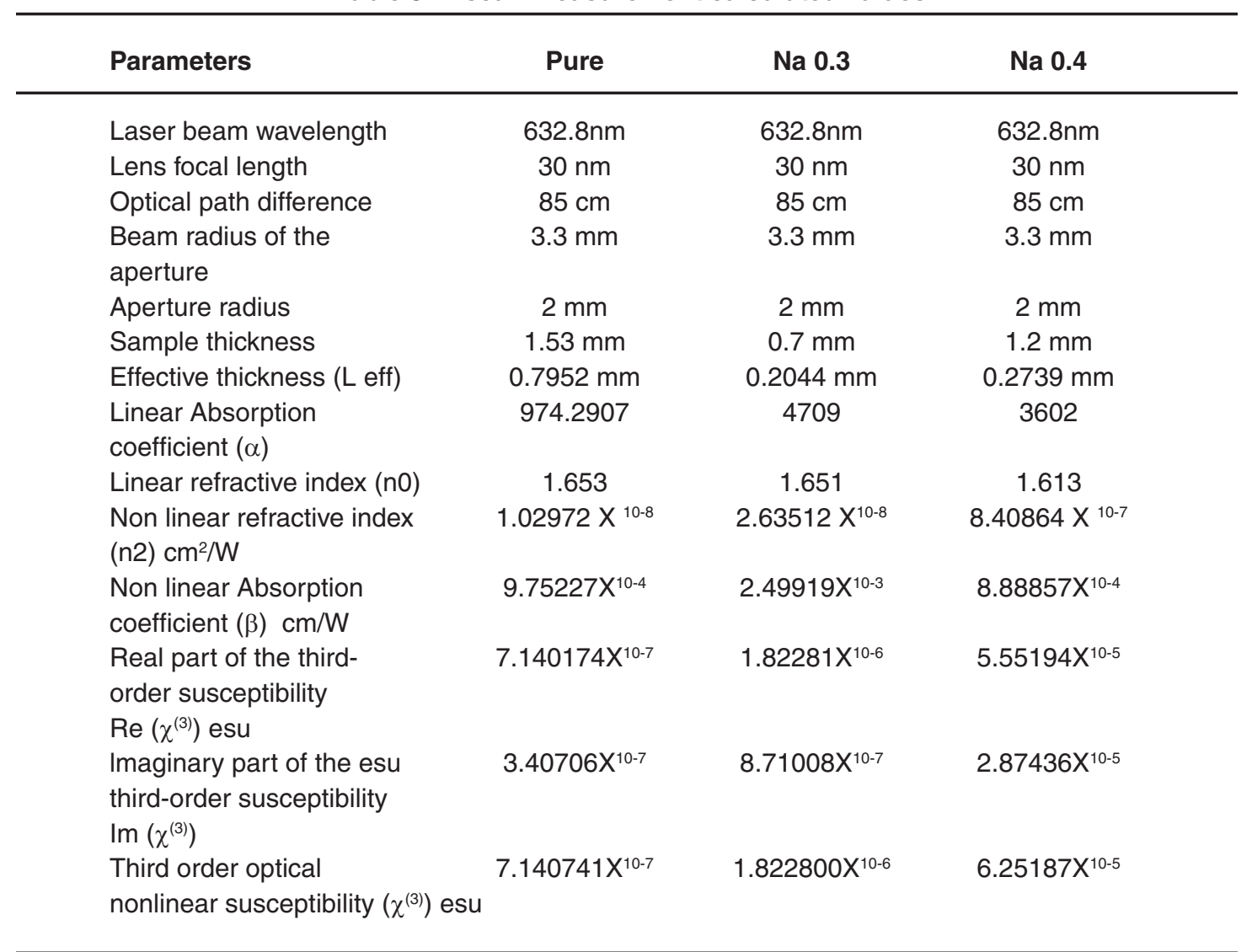

$$
\left|\chi^{(3)}\right|=\left[\left(\operatorname{Re}\left(\gamma^{(3)}\right)^{2}+\left(\operatorname{Im}\left(\gamma^{(3)}\right)^{2}\right]^{1 / 2}\right.\right.
$$

The recorded normalized transmittances in closed and open aperture curves for pure and doped crystals are given in Fig. 3 and 4, and the calculated values are tabulated in Table 1. The measured Third order non-linear properties confirm its suitability for non-linear optical devices such as optical limiting and optical switching.

From the open aperture curve pure LAA and $\mathrm{Na} 0.3$ dopend getting saturable absorption and 0.4 getting unsaturable absorption, because of percentage of Na. Non linear absorption coefficient(â) and third order optical nonlinear susceptibility $\left(\dot{\leftarrow}^{(3)}\right)$ of dopend is greater than as compared to the pure of LAA.

\section{CONCLUSION}

Single crystals of pure and $\mathrm{Na}$ doped L-arginine acetate (LAA) has been successfully grown from aqueous solution by slow evaporation technique. Powder X-ray diffraction studies confirm the monoclinic structure with space group $\mathrm{P}_{21}$. Third order nonlinear optical susceptibility $\left(\gamma^{3}\right) 7.1401 \times 10^{-7}$ esu (pure), $1.8228 \times 10^{-6}$ esu (Na 0.3 doped), $6.2518 \mathrm{X}$ $10^{-5}$ esu ( $\mathrm{Na} 0.4 \%$ doped) have been measured at $632.8 \mathrm{~nm}$ respectively. Thus these results revealed that LAA pure and doped crystal will be a potential candidate for third order NLO applications.

\section{ACKNOWLEDGMENTS}

The authors convey the heart full gratitude to the management of SRM University for their motivation and support. 


\section{REFERENCES}

1. Monaco, S.B.; Davis, L.E.; Velsko, S.P.; Wang, F.T.; Eimerl, D.; J. Crystal Growth. 1987, 85, 252-255.

2. Pal, T.; Kar,T.; Materials Chemistry and Physics. 2005, 91, 343- 347.

3. Zhao, W.; Palffy-Muhoray, P.Z.; Appl. Phys. Lett. 1993 63, 1613-1615.

4. Yin, M.; Li, H.P.; Tang, S.H.; Ji, W.;. Appl. Phys. B. 2000 70, 587-591.

5. Natarajan, V.; Sivanesan, T.; Pandi, S.; Indian J.Sci.Technol. 2010, 3 (6), 656-658.

6. Sivanesan, T.; Natarajan, V.; Pandi, S.; Indian J. Sci. Technol. 2010, 3 (6), 653- 655.

7. Tod, D.; Krauss Wise, F.W.; Appl. Phys. Lett. 1994, 65, 1739-1741.

8. Gomes, M.H.; De Araujo, G.; Opt. Commun. 1992, 87, 19-22.

9. Rangel-Rojo, R.; Kosa, T.; Hajito, E.; Ewen, P.J.S.; Owen A.E:, Kar, A.K.; Whereett, B.S.; Opt. Commun. 1994, 109, 145-150.

10. Wei, T.H.; Hagan, D.J.; Sence, M.J.; Van Stryland, E.W.; Perry, J.W.; Coulter, D.R.; Appl. Phys. B. 1992, 54, 46-51.

11. Zhang, W.; Zen, H.; Du, Y.; Han, Y.; Dong, F.;
Xia, Y.; J. Phys. B. 1993, 26, L451-L456

12. Paparo, D.; Maddalena, P.; Abbade, G.; Santamato, E.; Jannossy. Mol. Cryst. Liq. Cryst. 1994, 251, 73-84.

13. Li, L.; Yuan, HJ.; Hu, GH.; Palffy-Muthoray, .P;. . Liq. Cryst. 1994, 16, 703-712.

14. Lee Tutt, W.; Boggess, TF.; Prog. Quant. Elecr. 1993,17, 299-306.

(5. Fryad, Z.; Shane Namara, M.; Stevenso, O.; Callagham, J.; Weldon, D.; Blau, WJ.; 1993. Adv. Mater. 5, 930-936.

16. Balachandran, V.; Parimala, K.; Spectrochim acta. A. 2012, 95, 354-368.

17. Socrates, G.; Infrared and Raman of Characteristic Frequencies, Third ed., John Wiley and Sons Ltd., Chichester, 2001.

18. Van Stryland, E. M.; Sheik-Bahae, M.; Kuzyk, M. G.; Dirk, C.W.; Marcel Dekker Inc. 1998, 655-692.

19. Sabari Girisun, T. C.; Dhanuskod, S.; Mangalaraj, D.; . J. Current Applied Physics 2011, 11, 838-43.

20. Muralidharan, R.; Mohankumar. R.; Jayavel, R.; Ramasamyet, P.; Journal of Crystal Growth 2003,259,321-325. 